\title{
Prevalence of anosmia among COVID-19 patients in Taif City, Kingdom of Saudi Arabia
}

\author{
Adnan A. Mubaraki, MD, Ghaida T. Alrbaiai, Medical Student, Afnan K. Sibyani, Medical Student, \\ Rahaf M. Alhulayfi, Medical Student, Reema S. Alzaidi, Medical Student, Haneen S. Almalki, Medical Student.
}

\begin{abstract}
الاهداف : فقدان أو نقص حاسة الشم المرتبط بـ

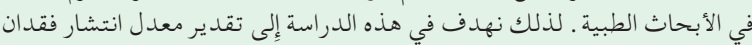
حاسة الشم.

الطريقة: تم إجراء هذه الدراسة بأثر رجعي على مرضى

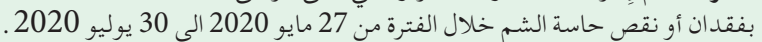

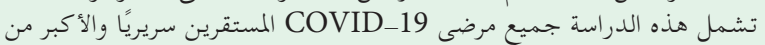

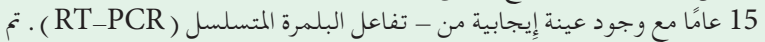

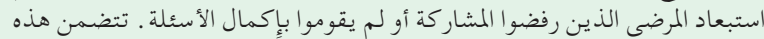

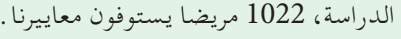

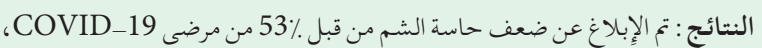

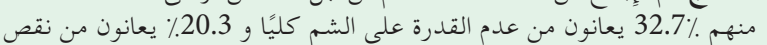

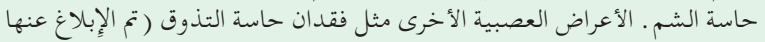

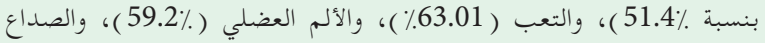

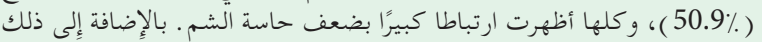

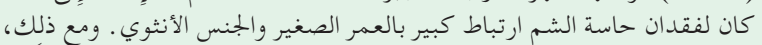

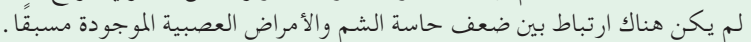
الاستنتاجات : أظهر نصف مرضى COVID_19 في الدراسة اختلالاً وظيفيًا في النيا

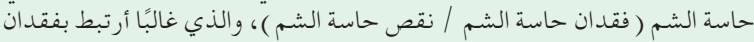

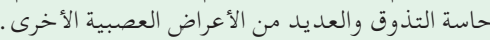

Objectives: To assess the prevalence of anosmia in coronavirus-19 (COVID-19) patients. Coronavirus-19related anosmia and hyposmia is a new emerging concept in the medical literature.

Methods: A retrospective study on COVID-19 patients with anosmia and hyposmia was performed during the period between May-July, 2020. The inclusion criteria were all clinically stable COVID-19 patients $>15$ years old with positive reverse transcription-polymerase chain reaction (RT-PCR). Patients who refused to participate or leave incomplete questions were excluded. In this study, we investigated 1022 patients who met our criteria.

Results: Olfactory dysfunction (OD) was reported by $53 \%$ of our COVID-19 patients, of which $32.7 \%$ were anosmic and $20.3 \%$ were hyposmic. Other neurological symptoms included ageusia (51.4\%), fatigue (63\%), myalgia (59.2\%), and headache (50.9\%), all of which showed significant association with OD. In addition, anosmia had a significant association with young age and female gender. However, there was no association between OD and pre-existing neurological disease.

Conclusion: Half of our COVID-19 patients presented OD (anosmia/hyposmia), which often associated with ageusia and many neurological symptoms.

Keywords: COVID-19, anosmia, olfaction dysfunction, ageusia.

Saudi Med J 2021; Vol. 42 (1): 38-43 doi: $10.15537 /$ smj.2021.1.25588

From the Department of Medicine (Mubaraki); and from the College of Medicine (Alrbaiai, Sibyani, Alhulayfi, Alzaidi, Almalki), Taif University, Taif, Kingdom of Saudi Arabia.

Received 10th September 2020. Accepted 23rd November 2020.

Address correspondence and reprint request to: Dr. Ghaida T. Alrbaiai, College of Medicine, Taif University, Taif, Kingdom of Saudi Arabia. E-mail: ghaidaturkii@outlook.sa

ORCID ID: https://orcid.org/0000-0002-2979-3652

The coronavirus-2019 disease (COVID-19) is an ongoing viral pandemic, which is caused by severe acute respiratory syndrome coronavirus- 2 (SARS-CoV-2). ${ }^{1,2}$ Coronavirus-19 was discovered firstly in Wuhan, China in December 2019.3,4 It is declared by the World Health Organization (WHO) as a global concern on March, 2020.5 Until June 2020 , the prevalence of confirmed cases worldwide was $8,708,008$ with 461,715 confirmed deaths. ${ }^{5}$ The spectrum of symptoms is greatly varying and typically includes high fever and dry cough. Other common respiratory symptoms include dyspnea and sore throat; gastrointestinal symptoms include nausea, vomiting, and diarrhea ${ }^{6-8}$ However, some patients present atypical symptoms including olfactory dysfunction (OD) 
either in the form of total loss (anosmia) or partial loss (hyposmia) and gustatory dysfunction (GD) in a sudden onset. ${ }^{9,10}$ It is well-known that upper respiratory tract infection viruses cause anosmia. ${ }^{11}$ Human strains of coronavirus invade the central nervous system through neuroepithelium and propagate within the olfactory bulb. ${ }^{12}$ Furthermore, OD in the form of anosmia with COVID-19 has been reported as one of the most common neurological symptoms. ${ }^{13,14}$ It mostly appears in asymptomatic patients or as an initial presentation without other symptoms. ${ }^{15}$ Of note, anosmia and ageusia are considered essential clues for the diagnosis of COVID-19. ${ }^{6}$ Recently, a multicentric European study conducted on 417 COVID-19 patients to investigate the occurrence of olfactory and GD showed that smell $(85.6 \%)$ and taste $(88.0 \%)$ disorders were observed in them. ${ }^{16}$ Another retrospective study, which was conducted in the United Kingdom to determine the prevalence of anosmia and ageusia in adult patients with COVID-19, showed that out of 141 patients, 77 (55\%) had anosmia and ageusia. ${ }^{17}$ Likewise, another study conducted in the United States of America on 237 patients with COVID-19 to establish anosmia as a reporting tool showed that $73 \%$ of them had anosmia. ${ }^{13}$ Subsequent research, which screened 1480 patients presented with flu-like symptoms and tested for COVID-19, showed that $68 \%$ of COVID-19 patients had anosmia, which was strongly correlated to ageusia compared to $16 \%$ in COVID-19 negative patients. ${ }^{18}$ Moreover, there were many studies aimed to investigate features and duration of anosmia, which concluded that the onset range was 1-21 days, and its duration range was 1-30 days in some patients with the mean of 8.9 days. ${ }^{17,19}$ A prospective study conducted in Daegu, Korea determined that median time for recovery was 7 days for anosmia and ageusia. ${ }^{6}$

Anosmia as a symptom of COVID-19 is an emerging evidence. However, there are limited studies conducted in the Kingdom of Saudi Arabia (KSA). Therefore, we aimed with this study to assess the prevalence of anosmia among COVID-19 patients in Taif, KSA.

Methods. This is a retrospective study, which was conducted during the period of May-July, 2020. It aimed to assess the prevalence of anosmia among COVID-19 patients in Taif, KSA and to evaluate its feature and duration. In addition to assess the association

Disclosure. Authors have no conflict of interests, and the work was not supported or funded by any drug company. between anosmia and common COVID-19 symptoms. The study was conducted on previously diagnosed COVID-19 patients, who were admitted at that time at King Faisal Medical Complex, Taif, KSA. Ethical approval was obtained from the Ethical Committee of Health Affairs, Taif, KSA.

Inclusion criteria were as followed: all COVID-19 patients who were $>15$ years old, COVID-19 positive by RT-PCR, and clinically able to be interviewed irrespectively to the disease severity. Patients who refused to participate or left in the middle of the interview were excluded.

Information was collected by telephone interviews that were conducted with all COVID-19 patients who were admitted in between 27 May and 30 July, 2020 and meet inclusion criteria and agreed to participate. The data included demographics (namely, age, gender, and nationality), previous history of olfactory and GD, current or previous treatment with chemotherapy or immunotherapy, and history of head and neck radiotherapy. If OD was present, information about its character (anosmia, hyposmia) and duration was collected. The presence of ageusia and its association with OD was assessed. The presence of typical COVID-19 symptoms and other neurological symptoms (headache, dizziness, disturbed level of consciousness, fatigue, myalgia, and seizure) was determined.

The data was analyzed using the Statistical Package for Social Sciences Version 23 (IBM Corp., Armonk, NY, USA) for Windows. For the comparison of continuous variables student's t-test was used, and Pearson's Chi-square test was used to determine the relationship of categorical variables.

Results. Out of the 1645 shortlisted patients with COVID-19, 305 patients were not contacted owing to the wrong telephone number or inability to reach them. In addition, 168 patients did not respond, and 150 patients refused to participate; thus, the response rate was $62.12 \%(\mathrm{n}=1022)$.

The overall prevalence of OD among COVID-19 patients was determined to be 53\%. Those with anosmia accounted for $32.7 \%$, and those with hyposmia accounted for $20.3 \%$ (Figure 1). When the prevalence of anosmia was correlated with the age of the participants, it was determined that 15-39 year-old patients had a comparatively higher anosmia prevalence than other age groups; this result showed a statistically significant association $\left(x^{2}[2,1022]=13.582, p=0.001\right.$, Table 1).

In our study, $39.1 \%$ of the participants were females and $60.9 \%$ were males. The prevalence of OD was much higher in females $(60.3 \%)$ than in males 
(56.5\%); this result showed a statistically significant relationship $\left(x^{2}[2,1022]=12.30, p<0.001\right)$. When we compared the prevalence of anosmia between Saudi and other nationalities, it was determined that Saudi citizens had a comparatively higher prevalence $(56.5 \%)$ than non-Saudis (49\%); this result was statistically significant $\left(x^{2}[2,1022]=5.46, p=0.019\right.$, Table 1$)$.

The study showed that $5.1 \%$ had the presence of neurological diseases and showed no significant association with anosmia $(p=0.527)$. However, some neurological symptoms in those patients were significantly associated with anosmia. Patients with multiple symptoms showed the higher prevalence of OD $(62.5 \%)$ than those who had only one symptom $\left(x^{2}[2,1022]=64.070, p<0.001\right.$, Table 2). The most common neurological symptom was fatigue $(63.1 \%)$ followed by myalgia (59.2\%) and headache (50.9\%), (Figure 2).

When we assessed the prevalence of OD in patients who underwent or were undergoing chemotherapy/

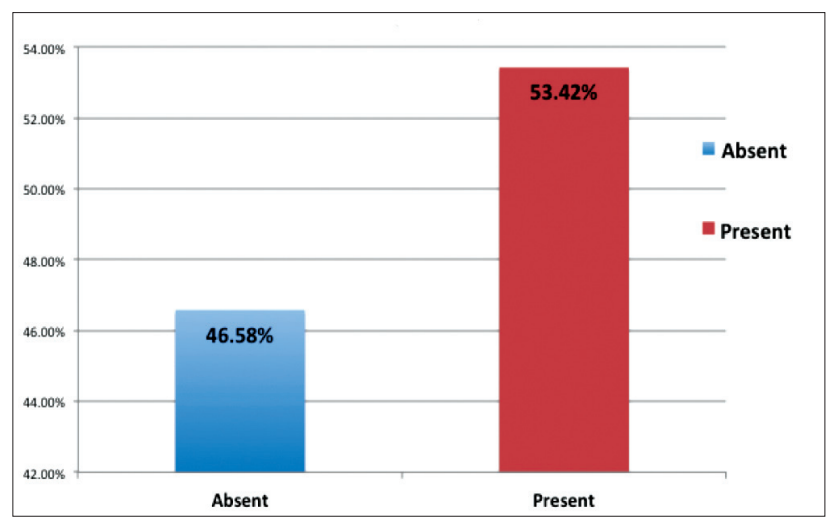

Figure 1 - Prevalence of olfactory dysfunction in covid-19 patients. immunotherapy, it was determined that there was no association $(p=0.779)$. In addition, there was no significant association observed between the prevalence of OD and the history of head and neck radiotherapy $(p=0.879)$. The prevalence of diabetes mellitus in these COVID-19 patients was 33.6\%; however, the prevalence of $\mathrm{OD}$ was higher in non-diabetic patients $(57 \%)$ than in diabetics $(46.4 \%)\left(x^{2}[2,1022]=10.368\right.$, $p=0.001$ ).

The mean duration of $\mathrm{OD}$ in our cohort was $10.8 \pm 9.7$ days; the mean duration of anosmia was $12.1 \pm 10.3$ days and that of hyposmia was $8.7 \pm 8.3$ days. The comparison of duration of OD between patients who had anosmia and hyposmia showed a statistically significant difference $(p<0.001$, Table 3$)$. The mean duration of ageusia in patients was found to be 10.4 \pm 9.1 that also showed a statistically significant difference between anosmia $(11.5 \pm 9.2$ days $)$ and hyposmia $(9.2 \pm 9.4$ days) $(p=0.010$, Table 3$)$.

In our study, the prevalence of abdominal pain and diarrhea in Covid-19 patients was $14 \%$, and that of ageusia was $51.4 \%$. In COVID-19 patients, the incidence of abdominal pain and diarrhea was comparatively higher in patients who had OD than in those who did not; this result showed a statistically significant association $\left(x^{2}(2,1022)=26.46, p<0.001\right.$, Table 4). There was a higher prevalence of ageusia in patients who had OD than those who did not have any smell problems; this result showed a statistically significant association $\left(x^{2}[2,1022]=598.98, p<0.001\right.$, Table 4). When we performed a multivariate logistic regression, it was determined that age $(\mathrm{OR}=0.726$ [0.60-0.88]) and gender $(\mathrm{OR}=1.81$ [1.38-2.39]) were independent risk factors for anosmia in COVID-19 patients.

Table 1 - Prevalence of ansonia and its relationship with sociodemographic details.

\begin{tabular}{|c|c|c|c|c|c|}
\hline \multirow[t]{2}{*}{ Variables } & \multicolumn{5}{|c|}{ Olfactory dysfunction after COVID-19 } \\
\hline & Absent & $\begin{array}{l}\text { Present } \\
\text { n (\%) }\end{array}$ & Total & Pearson chi-square & $P$-value* \\
\hline \multicolumn{6}{|l|}{ Age } \\
\hline $\begin{array}{l}15-39 \text { years } \\
40-95 \text { years } \\
\geq 60 \text { years }\end{array}$ & $\begin{array}{l}114(40.1) \\
231(45.7) \\
131(56.2)\end{array}$ & $\begin{array}{l}170(59.9) \\
274(54.3) \\
102(43.8)\end{array}$ & $\begin{array}{l}284(27.8) \\
505(49.4) \\
233(22.8)\end{array}$ & 13.582 & 0.001 \\
\hline \multicolumn{6}{|l|}{ Gender } \\
\hline $\begin{array}{l}\text { Female } \\
\text { Male }\end{array}$ & $\begin{array}{l}159(39.8) \\
317(51.0)\end{array}$ & $\begin{array}{c}241(60.3) \\
305(49)\end{array}$ & $\begin{array}{l}400(39.1) \\
622(60.9)\end{array}$ & 12.305 & $<0.001$ \\
\hline \multicolumn{6}{|l|}{ Nationality } \\
\hline $\begin{array}{l}\text { Saudi } \\
\text { Non-Saudi }\end{array}$ & $\begin{array}{c}236(43.5) \\
213(51)\end{array}$ & $\begin{array}{c}341(56.5) \\
205(49)\end{array}$ & $\begin{array}{l}604(59.1) \\
418(40.9) \\
\end{array}$ & 5.457 & 0.019 \\
\hline
\end{tabular}


Table 2 - Prevalence of anosmia and its relationship between other diseases and symptoms.

\begin{tabular}{|c|c|c|c|c|c|}
\hline \multirow[t]{2}{*}{ Variables } & \multicolumn{5}{|c|}{ Olfactory dysfunction after covid-19 } \\
\hline & Absent & Present & Total & Pearson Chi-square & $P$-value* \\
\hline \multicolumn{6}{|l|}{ Prevalence of neurological diseases } \\
\hline $\begin{array}{l}\text { No } \\
\text { Yes }\end{array}$ & $\begin{array}{r}454(46.8) \\
22(42.3)\end{array}$ & $\begin{array}{r}516(53.2) \\
30(57.7)\end{array}$ & $\begin{array}{r}970(94.9) \\
52 \quad(5.1)\end{array}$ & 0.401 & 0.527 \\
\hline \multicolumn{6}{|l|}{ Neurological symptoms } \\
\hline $\begin{array}{l}\text { No symptoms } \\
\text { Headache } \\
\text { Dizziness } \\
\text { Disturb level of consciousness } \\
\text { Fatigue } \\
\text { Myalgia } \\
\text { Multiple symptoms }\end{array}$ & $\begin{array}{r}129(66.2) \\
40(54.8) \\
2(40.0) \\
1(33.3) \\
44(65.7) \\
19(52.8) \\
241(37.5)\end{array}$ & $\begin{array}{r}66(33.8) \\
33(45.2) \\
3(60.0) \\
2(66.7) \\
23(34.3) \\
17(47.2) \\
402(62.5)\end{array}$ & $\begin{array}{rr}195 & (19.1) \\
73 & (7.1) \\
5 & (0.5) \\
3 & (0.3) \\
67 & (6.6) \\
36 & (3.5) \\
643 & (62.9)\end{array}$ & 64.070 & $<0.001$ \\
\hline \multicolumn{6}{|c|}{ History of chemotherapy or immunotherapy } \\
\hline $\begin{array}{l}\text { Present } \\
\text { Absent }\end{array}$ & $\begin{array}{r}6(42.9) \\
470(46.6)\end{array}$ & $\begin{array}{r}8(57.1) \\
538(53.4)\end{array}$ & $\begin{array}{r}14(1.4) \\
1008(98.6)\end{array}$ & 0.079 & 0.779 \\
\hline \multicolumn{6}{|c|}{ History of head and neck radiotherapy } \\
\hline $\begin{array}{l}\text { Present } \\
\text { Absent }\end{array}$ & $\begin{array}{r}20(45.5) \\
456(46.6)\end{array}$ & $\begin{array}{r}24(54.5) \\
522(53.4)\end{array}$ & $\begin{array}{rr}44 & (4.3) \\
879(95.7)\end{array}$ & 0.023 & 0.879 \\
\hline \multicolumn{6}{|l|}{ Diabetes mellitus } \\
\hline $\begin{array}{l}\text { Present } \\
\text { Absent }\end{array}$ & $\begin{array}{l}184(53.6) \\
292(43.0)\end{array}$ & $\begin{array}{l}159(46.4) \\
387(57.0) \\
\end{array}$ & $\begin{array}{l}343(33.6) \\
679(66.4) \\
\end{array}$ & 10.368 & 0.001 \\
\hline
\end{tabular}

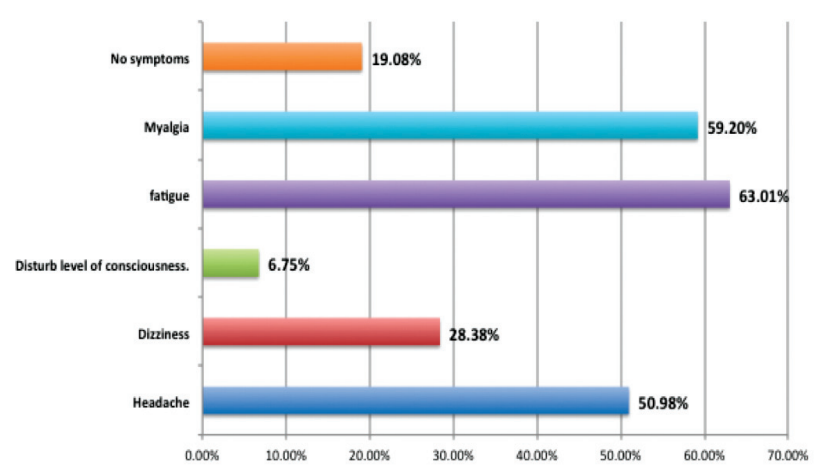

Figure 2 - Distribution of neurological symptoms in covid-19 patients.

Discussion. Coronavirus-19 is an active pandemic disease and is considered as a threat to the global health; there are many unanswered questions and updates regarding its clinical picture. In this study, we aimed to assess the prevalence of anosmia among COVID-19 patients in Taif, KSA and to evaluate its feature and duration.

In our study, the overall prevalence of OD was 53\%; of these patients, $32.7 \%$ reported having anosmia, while the rest $20.3 \%$ reported having hyposmia. The prevalence of OD in more than half of the patients agreed with a large cross-European study that showed an $85.6 \%$ prevalence of OD with the predominance of anosmia. We believe that the higher frequency in
Table 3 - Comparison of duration of olfactory dysfunction (students t-test).

\begin{tabular}{lccc}
\hline Variables & $\mathbf{n}$ & Mean \pm SD & $P$-value* \\
\hline Duration of olfactory & dysfunction & & \\
Anosmia & 331 & $12.1 \pm 10.3$ & \\
Hyposmia & 214 & $8.7 \pm 8.3$ & $<0.001$ \\
Total & 545 & $10.8 \pm 9.7$ & \\
Duration of ageusia & & & \\
Anosmia & 309 & $11.5 \pm 9.2$ & \\
Hyposmia & 166 & $9.2 \pm 9.4$ & 0.010 \\
Total & 475 & $10.4 \pm 9.1$ & \\
\multicolumn{4}{c}{} \\
\hline
\end{tabular}

the European study (85.6\% in their study compared to $53 \%$ in our study) is due to their cohort profiles, which were ambulatory patients who were consulted during ear-nose-throat (ENT) consultations. ${ }^{16}$ Another explanation for their higher prevalence is the ethnic difference of COVID-19 symptoms hypothesis. This high prevalence of both studies supports the ability of coronavirus to affect the olfactory neuron function and the importance of considering anosmia as a predictor for COVID-19 infection.

Ageusia is one of the unpredicted symptoms of COVID-19, which has been reported in the literature since the beginning of the pandemic. In our study, the prevalence of ageusia was determined to be $51.4 \%$; 
Table 4 - Olfactory dysfunction and its relationship with ageusia and abdominal pain/diarrhea.

\begin{tabular}{|c|c|c|c|c|c|}
\hline \multirow[t]{2}{*}{ Variables } & \multicolumn{5}{|c|}{ Olfactory dysfunction after covid-19 } \\
\hline & Absent & $\begin{array}{l}\text { Present } \\
\text { n (\%) }\end{array}$ & Total & Pearson chi-square & $P$-value* \\
\hline \multicolumn{6}{|l|}{ Ageusia } \\
\hline $\begin{array}{l}\text { Present } \\
\text { Absent }\end{array}$ & $\begin{array}{c}50(9.5) \\
423(85.1)\end{array}$ & $\begin{array}{c}309(58.9) \\
25(5.0)\end{array}$ & $\begin{array}{l}525(51.4) \\
497(48.6)\end{array}$ & 589.51 & $<0.001$ \\
\hline \multicolumn{6}{|c|}{ Abdominal pain and diarrhea } \\
\hline $\begin{array}{l}\text { Present } \\
\text { Absent }\end{array}$ & $\begin{array}{c}37(26.4) \\
439(49.8)\end{array}$ & $\begin{array}{l}103(73.6) \\
443(50.2)\end{array}$ & $\begin{array}{l}140(13.7) \\
882(86.3)\end{array}$ & 26.462 & $<0.001$ \\
\hline
\end{tabular}

likewise, a recently published study by Patel et al, ${ }^{17}$ has reported the high prevalence of ageusia of $55 \%$. The mean duration of OD and ageusia depended on the neurosensory receptor's turnover after the invasion. Our results show that they are nearly similar because, namely, $10.8 \pm 9.7$ days for OD and 10.4 \pm 9.04 days for ageusia. This result agrees with a previously published result by Lee et al. ${ }^{6}$

Additionally, there is a significant association between olfactory and gustatory dysfunction in our COVID-19 patients, which is equivalent to the results of Lechien et al and Luers et al. ${ }^{16,20}$ The close association between anosmia and ageusia has been explained in many ways in the literature. Hummel et $\mathrm{al}^{21}$ has stated that basic taste (sour, sweet, bitter, salty, and umami) are identified only by the gustatory system (glossopharyngeal, facial, and vagal nerves), while the culinary experience is mostly determined by the olfactory nerve.

Regarding demographic factors, female gender and young age are significantly associated with anosmia, which is similar to the data published by Paderno et $\mathrm{al}^{22,23}$ and is most likely due to differences in the inflammatory reactions between the 2 genders.

Neurologists and neurological journals have discussed neurological manifestations in COVID-19 since the beginning of the pandemic. In our population, fatigue (63.01\%), myalgia (59.2\%), and headache (50.9\%) are the most prevalent neurological symptoms, these results matched those in other published studies. ${ }^{16,18,24,25}$ Moreover, the prevalence of OD in patients with multiple neurological symptoms is higher than that in those who have only one symptom, which indicates that human coronaviruses can invade central nervous system (CNS) and cause many neurological symptoms at the same time. In addition, this result may reflect the neuroinvasive actions of coronavirus by the retrograde neuronal route through olfactory neuroepithelium.

In addition, because our results do not show significant association between OD and diabetes mellitus, diabetic polyneuropathy is not involved in
OD with COVID-19 infection, which is similar to the result of Lechien et al. ${ }^{16}$ In addition, there is no significant association between $\mathrm{OD}$ and pre-existing neurological diseases. This may be due to the presence of anosmia in the mild forms of the disease. In contrast, pre-existing neurological disorders (namely, myasthenia gravis, lambert eaton myasthenic syndrome, or multiple sclerosis) put patients at a higher risk for the severe form of COVID-19 disease, as has been stated by a review published in May 2020. ${ }^{16,24}$

Regarding the association of OD with typical COVID-19 symptoms, diarrhea and abdominal pain are more prevalent in patients with olfactory dysfunction, which has been also reported in Klopfenstein et al. ${ }^{20}$

The contagious nature of the disease and preventive measures lead to the lack of clinical assessment, which is a major limitation of this and other similar studies. Also, there is a possibility of recall bias since this is a retrospective study. Our recommendation for future researchers to carry out a prospective study and psychophysical assessment is recommended for more accurate results.

Study limitations. This is one of few studies that investigate COVID-19-related OD among quite numerous population $(n=1022)$ on general, and it is one of the few studies on COVID-19 olfactory dysfunction in KSA especially.

In conclusion, $\mathrm{OD}$ and ageusia are considered to be highly prevalent symptoms. They deserve special attention because they are highly suggestive for the COVID-19 infection, especially when it is associated with other neurological manifestations such as fatigue, headache, and myalgia.

Acknowledgment. The authors gratefully acknowledge the data collectors of this study. Ahad A. Alnemari, Ghadi N. Alotibi, Maram M. Altalhi, Saad E. Althuwaybi, Samar M. Koursan who helped in explaining this study goal and in data collection. Also, we would like to thank Falcon editing services for English language editing (https:// falconediting.com/) for language editing. 


\section{References}

1. Guan WJ, Ni ZY, Hu Y, Liang WH, Ou CQ, He JX, et al. Clinical characteristics of coronavirus disease 2019 in China. $N$ Engl J Med 2020; 382: 1708-1720.

2. Ramanathan K, Antognini D, Combes A, Paden M, Zakhary $\mathrm{B}$, Ogino $\mathrm{M}$, et al. Planning and provision of ECMO services for severe ARDS during the COVID-19 pandemic and other outbreaks of emerging infectious diseases. Lancet Respir Med 2020; 8: 518-526.

3. Li Q, Guan X, Wu P, Wang X, Zhou L, Tong Y, et al. Early transmission dynamics in Wuhan, China, of novel coronavirusinfected pneumonia. N Engl J Med 2020; 382: 1199-1207.

4. Wu Z, McGoogan JM. Characteristics of and important lessons from the coronavirus disease 2019 (COVID-19) outbreak in China: summary of a report of 72314 cases from the Chinese center for disease control and prevention. JAMA 2020; 323: $1239-1242$.

5. World Health Organization. Coronavirus disease (COVID-19) pandemic [Internet]. [Updated 2019; Accessed 2020 June 22]. Available from: https://www.who.int/emergencies/diseases/ novel-coronavirus-2019

6. Lee Y, Min P, Lee S, Kim SW. Prevalence and duration of acute loss of smell or taste in COVID-19 patients. J Korean Med Sci 2020; 35: e174.

7. Chen N, Zhou M, Dong X, Qu J, Gong F, Han Y, et al. Epidemiological and clinical characteristics of 99 cases of 2019 novel coronavirus pneumonia in Wuhan, China: a descriptive study. Lancet 2020; 395: 507-513.

8. Hui DS, I Azhar E, Madani TA, Ntoumi F, Kock R, Dar $\mathrm{O}$, et al. The continuing 2019-nCoV epidemic threat of novel coronaviruses to global health - The latest 2019 novel coronavirus outbreak in Wuhan, China. Int J Infect Dis 2020; 91: 264-266.

9. Vaira LA, Salzano G, Deiana G, De Riu G. In response to anosmia and ageusia: common findings in COVID-19 patients. Laryngoscope 2020; 130: E695.

10. Gane SB, Kelly C, Hopkins C. Isolated sudden onset anosmia in COVID-19 infection. A novel syndrome? Rhinology 2020; 58: 299-301.

11. Eccles R. Understanding the symptoms of the common cold and influenza. Lancet Infect Dis 2005; 5: 718-725.

12. Dubé M, Le Coupanec A, Wong AHM, Rini JM, Desforges M, Talbot PJ. Axonal transport enables neuron-to-neuron propagation of human coronavirus OC43. J Virol 2018; 92: e00404-e00418.

13. Kaye R, Chang CWD, Kazahaya K, Brereton J, Denneny JC 3rd. COVID-19 anosmia reporting tool: initial findings. Otolaryngol Head Neck Surg 2020; 163: 132-134.
14. Hopkins C, Kumar N. Loss of sense of smell as marker of COVID-19 infection [Internet]. ENT UK; 2020 [Please cite date accessed]. Available from: https://www.entuk.org/sites/ default/files/files/Loss\%20of\%20sense $\% 20$ of\%20smell\%20 as\%20marker\%20of\%20COVID.pdf

15. Niazkar HR, Zibaee B, Nasimi A, Bahri N. The neurological manifestations of COVID-19: a review article. Neurol Sci 2020; 41: 1667-1671.

16. Lechien JR, Chiesa-Estomba CM, De Siati DR, Horoi M, Le Bon SD, Rodriguez A, et al. Olfactory and gustatory dysfunctions as a clinical presentation of mild-to-moderate forms of the coronavirus disease (COVID-19): a multicenter European study. Eur Arch Otorhinolaryngol 2020; 277: 2251-2261.

17. Patel A, Charani E, Ariyanayagam D, Abdulaal A, Denny SJ, Mughal N, et al. New-onset anosmia and ageusia in adult patients diagnosed with SARS-CoV-2 infection. Clin Microbiol Infect 2020; 26: 1236-1241.

18. Yan CH, Faraji F, Prajapati DP, Boone CE, DeConde AS. Association of chemosensory dysfunction and COVID-19 in patients presenting with influenza-like symptoms. Int Forum Allergy Rhinol 2020; 10: 806-813.

19. Klopfenstein T, Kadiane-Oussou NJ, Toko L, Royer PY, Lepiller Q, Gendrin V, et al. Features of anosmia in COVID-19. Med Mal Infect 2020; 50: 436-439.

20. Luers JC, Rokohl AC, Loreck N, Wawer Matos PA, Augustin $\mathrm{M}$, Dewald F, et al. Olfactory and gustatory dysfunction in coronavirus disease 2019 (COVID-19). Clin Infect Dis 2020; 71: 2262-2264.

21. Hummel T, Heilmann S, Landis BN, et al. Perceptual differences between chemical stimuli presented through the ortho- or retronasal route. Flavour and fragrance journal 2006; 21: 42-47.

22. Paderno A, Schreiber A, Grammatica A, Raffetti E, Tomasoni M, Gualtieri T, et al. Smell and taste alterations in COVID-19: a cross-sectional analysis of different cohorts. Int Forum Allergy Rhinol 2020; 10: 955-962.

23. Speth MM, Singer-Cornelius T, Oberle M, Gengler I, Brockmeier SJ, Sedaghat AR. Olfactory dysfunction and sinonasal symptomatology in COVID-19: prevalence, severity, timing, and associated characteristics. Otolaryngol Head Neck Surg 2020; 163: 114-120.

24. Zubair AS, McAlpine LS, Gardin T, Farhadian S, Kuruvilla DE, Spudich S. Neuropathogenesis and neurologic manifestations of the coronaviruses in the age of coronavirus disease 2019: a review. JAMA Neurol 2020; 77: 1018-1027.

25. Asadi-Pooya AA, Simani L. Central nervous system manifestations of COVID-19: a systematic review. J Neurol Sci 2020; 413: 116832 . 